\title{
Sinking particle properties from polyacrylamide gels during the KErguelen Ocean and Plateau compared Study (KEOPS): Zooplankton control of carbon export in an area of persistent natural iron inputs in the Southern Ocean
}

\section{F. Ebersbach ${ }^{1}$}

Antarctic Climate and Ecosystems (ACE) Cooperative Research Centre, Institute of Antarctic and Southern Ocean Studies (IASOS), University of Tasmania, Hobart, 7001, Australia; Carl von Ossietzky University, Oldenburg, Germany

T. W. Trull

Antarctic Climate and Ecosystems (ACE) Cooperative Research Centre, Institute of Antarctic and Southern Ocean Studies (IASOS), University of Tasmania, Hobart, 7001, Australia; Commonwealth Scientific and Industrial Research Organization (CSIRO) Marine and Atmospheric Research, Hobart, 7001, Australia

\begin{abstract}
The Kerguelen ocean and plateau compared study (KEOPS) examined the origin of elevated phytoplankton biomass in naturally iron-fertilized waters over the Kerguelen plateau during midsummer (January-February 2005). We report sinking particle characteristics determined from image analysis of thousands of individual particles collected in viscous polyacrylamide gels placed in free-drifting sediment traps at two sites: a high phytoplankton biomass site over the central plateau (A3) and a moderate biomass site at its periphery (C5). The particles were divided into three types (1) oval fecal pellets, (2) cylindrical fecal pellets, and (3) aggregates. The aggregates were most abundant and mainly consisted of agglomerations of the cylindrical fecal pellets. Conversion of the pellet and aggregate volumes to carbon contents suggests export fluxes of 50-60 mg C m $\mathrm{m}^{-2} \mathrm{~d}^{-1}$ at $100-\mathrm{m}$ depth, in reasonable agreement with independent estimates from carbon and ${ }^{234} \mathrm{Th}$ measurements. Our observation that the majority of the particle flux was processed through the heterotrophic foodweb contrasts with the results of artificial iron-fertilization experiments and with models for export from productive diatomdominated waters that emphasize direct export of phytoplankton detritus. The KEOPS results may offer more appropriate scaling for the response of ecosystem structure and carbon export to persistent iron fertilization in the Southern Ocean.
\end{abstract}

The Kerguelen Ocean and Plateau compared Study (KEOPS) program carried out a survey of biogeochemical processes over the Kerguelen plateau in the Southern Ocean. The primary objective was to determine the cause of

\footnotetext{
1 Present address: Alfred Wegener Institute for Marine and Polar Research (AWI), Am Handelshafen 12, 27570 Bremerhaven, Germany.

\section{Acknowledgments}

We thank KEOPS chief scientists Stephane Blain and Bernard Queguiner (Université de Marseille) for inviting our participation, Dan Mclaughlin Commonwealth Scientific and Industrial Research Organization (CSIRO) and Stephen Bray Antarctic Climate and Ecosystems (ACE) for trap preparation, Clodagh Moy (ACE) for gel preparation, and Tom Remenyi (ACE), Pierre Sangiardi, and Christophe Guillerm for onboard preparation of replacement trap arrays. Ron Thresher, Rob Guerney, and Jawahar Patil provided access and aid in the CSIRO microscopy laboratory, and Karin Beaumont (Institute of Antarctic and Southern Ocean Studies) and Stephanie Wilson (Virginia Institute of Marine Sciences) gave advice on fecal pellet identification and carbon content estimation. Funding was provided by the Australian Commonwealth Cooperative Research Centre Program, the French-Australian Science and Technology Cooperation (A. Bowie, T. Trull et al. award FR040170), the Australian Antarctic Science Program (T. Trull et al. AAS1156), and loan of equipment from the U.S. National Science Foundation (K. Buesseler, T. Trull et al. award 0301139). We are grateful for constructive reviews and editorial input that significantly improved this paper.
}

persistently high phytoplankton biomass in this region, as seen in SeaWiFS and MODIS satellite images of ocean color. Enhanced iron supply from plateau sediments appears to play the key role (Blain et al. 2007). The iron input increases phytoplankton growth rates and draws down surface carbon dioxide partial pressure by more than $700 \mathrm{~Pa}(70 \mu \mathrm{atm})$ although full use of macronutrients (phosphate, nitrate, silicate) is still not achieved (Blain et al. 2007). Thus the Kerguelen plateau offers an opportunity to examine the influence of iron on ocean biogeochemistry and carbon sequestration beyond what can be achieved with short-term iron "fertilization" experiments (Buesseler and Boyd 2003).

The carbon sequestration accompanying the iron inputs over the Kerguelen plateau depends on the transfer of carbon from surface waters to the ocean interior in sinking particles. The magnitude of this export production is generally linked to primary production, although the relationship can be complex and strongly dependent on ecosystem structure (Michaels and Silver 1988; Boyd and Newton 1999). Export estimates from the ${ }^{234} \mathrm{Th}$ deficit method during KEOPS suggest that particulate organic carbon (POC) export over the plateau was approximately twice that in adjacent high-nutrient low-chlorophyll (HNLC) waters but that the efficiency of export as a fraction of primary production was lower over the plateau ( $\sim 16 \%$ to $28 \%)$ than in the HNLC waters where it reached nearly 60\% (Savoye et al. 2006). 
A first step in determining the ecosystem processes responsible for POC export is to characterize the sinking particles, often by their collection in sediment traps. This has significant compromises because the particles can disaggregate or form new agglomerations within the trap. An improvement is the use of polyacrylamide gels within sediment traps (Lundsgaard 1995; Waite and Nodder 2001). With viscosity similar to honey, these chemically inert gels provide a slow deceleration of sinking particles and isolate the particles from each other in their original forms.

Here we report sinking particle characteristics determined from polyacrylamide gels in short-term free-drifting sediment trap deployments during KEOPS. The observations suggest that export was dominated by zooplankton fecal pellets - sinking both individually and in larger aggregates, and that the sinking flux decreased rapidly with depth. This situation is in considerable contrast to the results of Southern Ocean short-term iron-fertilization experiments, in which zooplankton responses have generally (Boyd et al. 2000; Coale et al. 2004) but not always (Peeken et al. 2006) been muted.

\section{Materials and methods}

Site description-The KEOPS voyage occupied three east-west transects over and to the east of the Kerguelen plateau (Fig. 1), and singled out two "reference" stations for repeat visits-A3 at the epicenter of the high, chlorophyll $a(\mathrm{Chl} a)$ region, and $\mathrm{C} 11$ at the southeast extreme of the study region in low-Chl $a$ waters. Deployment of free-drifting sediment traps was originally planned for these sites, but loss of equipment required these plans to be modified, and samples were collected twice at A3 and once at a moderate Chl $a$ concentration site (C5) along the southern periphery of the plateau. As summarized in Table 1, the traps were deployed at four depths below the mixed layer (which was relatively constant at 70 $\pm 10 \mathrm{~m}$ throughout the region; Blain et al. 2007).

The pattern of regional chlorophyll accumulation was relatively constant during the KEOPS study period (18 January to 13 February 2005) in terms of its major features of elevated biomass over the plateau and low biomass off the plateau to the south and east. Placed in a seasonal context, the Chl $a$ over the plateau increased strongly in October and November, reached maximum levels of $\sim 2.5 \mu \mathrm{g} \mathrm{L}^{-1}$ in December and January, and then slowly declined through the shipboard study period to less than $0.5 \mu \mathrm{g} \mathrm{L}^{-1}$ by early March (Blain et al. 2007). In keeping with the biomass distributions, surface mixed layer nutrient levels were lower over the plateau than at the C11 HNLC site (Blain et al. 2007). Primary production estimated from small-bottle short-term ${ }^{14} \mathrm{C}$ incubations during the shipboard observations was moderate at the A3-plateau and C5-bloom periphery sites and lower at the C11-HNLC site ( $\sim 300,200$, and $100 \mathrm{mg} \mathrm{C} \mathrm{m}^{-2} \mathrm{~d}^{-1}$, respectively, Griffiths and Uitz 2006).

All three trap deployment sites exhibited similar phytoplankton communities dominated by large diatoms, although pigment analyses suggested that the C5 site had

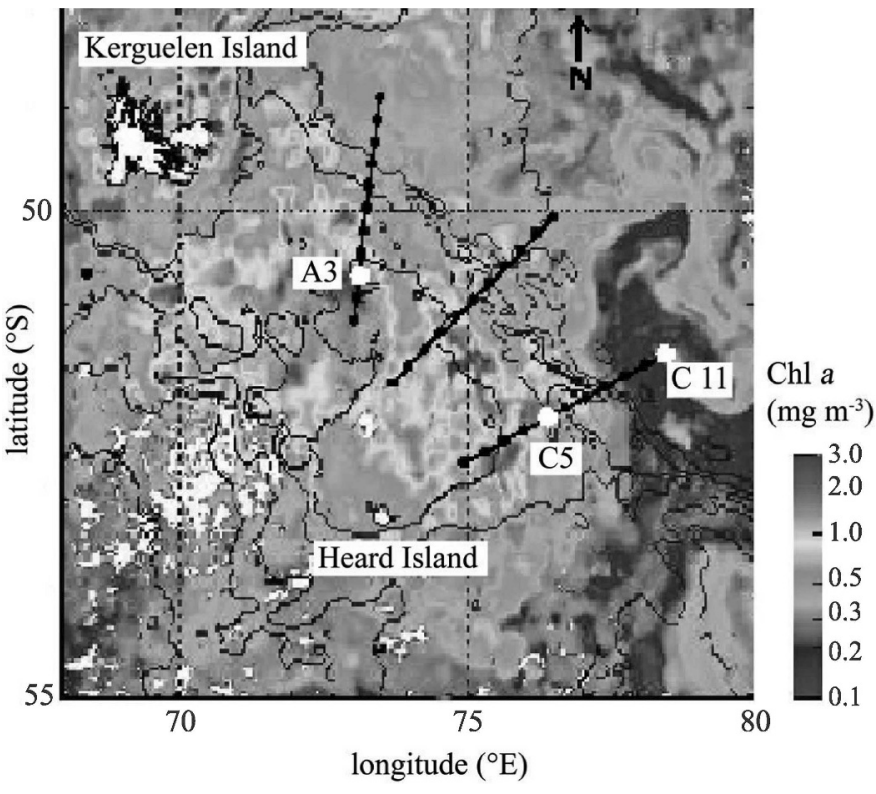

Fig. 1. Map of KEOPS cruise track, bathymetry, MODIS $\mathrm{Chl} a$, and sediment trap deployment locations. In white are Kerguelen Island at the top left and Heard Island at the lower center (near $53^{\circ} \mathrm{S}, 74^{\circ} \mathrm{E}$ ). Bathymetric contours are at $500-\mathrm{m}$ intervals. Eleven stations were carried out along each of three east-west transects-referred to as A, B, C from north to south. Sta. A3 was at the epicenter of the biomass-rich region and served as the reference high-biomass site. Gels were deployed and recovered there twice, and once at Sta. C5 near the 1,000-m contour at the southeast periphery of the plateau in the presence of low to moderate biomass. Sta. C11 at the eastern extreme provided the HNLC reference site, but no traps were deployed there because of earlier equipment failures. Table 1 provides more details of the gel deployments.

a somewhat larger proportion of nondiatom phytoplankton than either the A3 or C11 sites (Griffiths and Uitz 2006). Total ${ }^{234} \mathrm{Th}$ inventories observed in the water column, combined with $\mathrm{C}:{ }^{234} \mathrm{Th}$ ratio estimates from sediment trap and large volume filtrations, suggest relatively high POC export from all three of these sites (Savoye et al. 2006). At the A3 bloom site, POC export at $100-\mathrm{m}$ depth varied in the range $120-480 \mathrm{mg} \mathrm{m}^{-2} \mathrm{~d}^{-1}$ over three visits, and was $240-300 \mathrm{mg} \mathrm{m}^{-2} \mathrm{~d}^{-1}$ during the A3f trap deployment, equivalent to $\sim 28 \%$ of primary production. At the C11 HNLC site, this export was $\sim 144 \mathrm{mg}$ $\mathrm{m}^{-2} \mathrm{~d}^{-1}$, which was $\sim 58 \%$ of the primary production. At the bloom periphery site $\mathrm{C} 5$, the export was $\sim 108 \mathrm{mg}$ $\mathrm{m}^{-2} \mathrm{~d}^{-1}$, but this was only $\sim 21 \%$ of the primary production. Thus, the traps were deployed in central and peripheral regions of the elevated biomass region over the Kerguelen plateau, under conditions of moderate production and export toward the end of the annual diatomdominated phytoplankton "bloom."

Sediment trap deployments-The gels were prepared following the method of Lundsgaard (1995), with slight modifications. Prior to the expedition, Southern Ocean nutrient replete seawater was filtered through a glass fiber filter (nominal $0.8-\mu \mathrm{m}$ pore size) and $20 \mathrm{~g} \mathrm{~L}^{-1} \mathrm{NaCl}$ was 
Table 1. Sediment trap deployments.

\begin{tabular}{|c|c|c|c|c|c|c|c|}
\hline Site & Depths (m) & Start date & End date & Duration & Start position & End position & Drift $(\mathrm{km})$ \\
\hline A3i & 200 & $\begin{array}{c}03 \mathrm{Feb} 2005 \\
21: 36 \mathrm{~h}\end{array}$ & $\begin{array}{c}04 \text { Feb } 2005 \\
17: 11 \mathrm{~h}\end{array}$ & $18 \mathrm{~h} 35 \mathrm{~min}$ & $\begin{array}{l}50^{\circ} 37.80^{\prime} \mathrm{S}, \\
72^{\circ} 04.80^{\prime} \mathrm{E}\end{array}$ & $\begin{array}{l}50^{\circ} 15.60^{\prime} \mathrm{S}, \\
72^{\circ} 34.00^{\prime} \mathrm{E}\end{array}$ & 32 \\
\hline $\mathrm{C} 5$ & $\begin{array}{l}100,200,330 \\
430\end{array}$ & $\begin{array}{c}07 \text { Feb } 2005 \\
07: 21 \mathrm{~h}\end{array}$ & $\begin{array}{c}08 \text { Feb } 2005 \\
06: 55 \mathrm{~h}\end{array}$ & $23 \mathrm{~h} 34 \mathrm{~min}$ & $\begin{array}{c}52^{\circ} 27.43^{\prime} \mathrm{S}, \\
75^{\circ} 36.06^{\prime} \mathrm{E}\end{array}$ & $\begin{array}{c}52^{\circ} 13.87^{\prime} \mathrm{S}, \\
75^{\circ} 43.67^{\prime} \mathrm{E}\end{array}$ & 16 \\
\hline A $3 f$ & $\begin{array}{l}100,200,330 \\
430\end{array}$ & $\begin{array}{c}12 \text { Feb } 2005 \\
08: 09 \mathrm{~h}\end{array}$ & $\begin{array}{c}13 \text { Feb } 2005 \\
08: 19 \mathrm{~h}\end{array}$ & $24 \mathrm{~h} 10 \mathrm{~min}$ & $\begin{array}{c}50^{\circ} 37.73^{\prime} \mathrm{S}, \\
72^{\circ} 00.01^{\prime} \mathrm{E}\end{array}$ & $\begin{array}{c}50^{\circ} 35.62^{\prime} \mathrm{S}, \\
72^{\circ} 11.22^{\prime} \mathrm{E}\end{array}$ & 8 \\
\hline
\end{tabular}

added to increase its density. Acrylamide (16 weight percent) was dissolved in this solution and polymerized to form $\sim 4$ $\mathrm{cm}$ thick gels in containers with optically clear polycarbonate bottoms. No poisons, stains, or buffers were used.

A layer of filtered seawater amended with $10 \mathrm{~g} \mathrm{~L}^{-1} \mathrm{NaCl}$ was placed over the gels several days before deployment to allow a viscosity gradient of $\sim 1-\mathrm{cm}$ thickness to develop to ensure slow deceleration of sinking particles entering the gel. This ensures that particles enter the gel without contacting an interface that might alter their forms. Our concentration of acrylamide was twice that used in many previous studies (Waite and Nodder 2001; Whiteley 2003; Waite et al. 2005). This prevents flow of the gel during recovery and slows particle sinking rates sufficiently that they accumulate at $\sim 1$ $\mathrm{cm}$ depth within the gel where they are easily photographed in a single field of view. The particles then take several weeks to months to settle to the bottom of the containers. During this period they exhibit some degradation (loss of color, minor disaggregation that spreads their shapes isotropically) but show little sign of changes in form attributable to deformation by the gel (little or no flattening of the shapes in the vertical direction).

The gels were deployed in cylindrical traps (12-cm diameter by $60-\mathrm{cm}$ long), fitted with slightly conical bottoms with a central drain valve. The gels completely covered the bottom of the tubes, preventing particles from settling outside the gel and potentially being resuspended and entering the gel in altered form. This is an advance from previous approaches that placed small Petri dishes in the center of trap tubes (Waite and Nodder 2001; Whiteley 2003; Waite et al. 2005). To minimize possible alteration of sinking particles, no baffles were used. Brine (filtered seawater amended with $10 \mathrm{~g} \mathrm{~L}^{-1} \mathrm{NaCl}$ ) was carefully added to cover the gel to a depth of one trap diameter and was overlain with filtered seawater to fill the trap tube.

The individual trap tubes were spaced along a low-drag (5-mm diameter) plastic-jacketed wire (with a $20-\mathrm{kg}$ weight at the end) beneath a surface float equipped with a flashing light and an Argos/global positioning system beacon, and released to drift freely for $\sim 24 \mathrm{~h}$ (further details are given in Table 1). The trap at $200 \mathrm{~m}$ was configured differently than the others. It was attached with its top level with a larger cylindrical trap (2-m long, 60-cm diameter PPS3/3 trap, Technicap, France) used to collect particles for separate chemical studies (Savoye et al. 2006; Trull unpubl. data).

The trap deployments at site C5 and during the final deployment at site A3 were carried out in moderate winds $\left(5-10 \mathrm{~m} \mathrm{~s}^{-1}\right)$ and seas $(2-3 \mathrm{~m})$ with little difficulty. The two deeper tubes were successfully and rapidly deployed and recovered with essentially no loss of trap fluid, with little tilting of the traps and without any significant time spent in the mixed layer (a few minutes at most). Conditions for the 200-m tubes attached to the PPS3 sediment trap were also relatively benign but did involve considerable tilting of the tubes during deployment when slow filling and sinking of the PPS3 trap kept the tubes close to horizontal for several minutes. Fortunately, recovery showed that the gels did not flow out during this period and still covered the full expanse of the sediment trap bases. Recovery also involved greater tilting of the 100-m traps because of the higher drag of the PPS3 trap (up to 30 degrees from the vertical for up to $10 \mathrm{~min}$ ), and the gel-brine interface for these traps was $\sim 10$ degrees from horizontal on recovery but showed no significant signs of flow within the gel having disturbed the particle distributions.

In contrast, the initial deployment at site A3 (on 03-04 February 2005, referred to as A3i) experienced difficulties during recovery in higher winds $\left(10-13 \mathrm{~m} \mathrm{~s}^{-1}\right)$ and seas (4$5 \mathrm{~m})$ as the array became snagged under the hull and was dragged for $\sim 30 \mathrm{~min}$. On recovery the two gel tubes mounted on the PPS3 trap at $200 \mathrm{~m}$ were found to have flowed to angles of approximately 30 and 45 degrees from horizontal. The more disturbed gel showed signs of slumping that happened as seawater poured from the tube during recovery; therefore, it was not examined further. The other gel was in reasonable condition but showed a much greater amount of individual algal cells than those from the A3f and C5 deployments, suggesting they may have entered the trap as it was dragged near the surface. For this reason we focus primarily on the results of the C5 and final A3 (12-13 February 2005, referred to as A3f) deployments in the discussion below. We do present the A3i results, but they must be viewed with considerable caution.

Immediately on recovery the overlying seawater in the gel cups was carefully removed with a $50-\mathrm{ml}$ plastic syringe equipped with a short length of fine-bore tubing (which allows seawater but not the viscous gel to be removed), and the cups were sealed and stored at $4{ }^{\circ} \mathrm{C}$. This rapid removal of overlying seawater limits the collection of particles that entered the tube during its passage through the mixed layer on recovery, without removing particles that settled into the gel during deployment.

Gel microscopy and image analysis-The gels were examined onboard the ship within a few hours of recovery using low magnification stereomicroscopy $(6.5$ to $\times 50)$ and again in the laboratory 4 months after collection, using high magnification stereomicroscopy (Leica MZ 16 FA at 


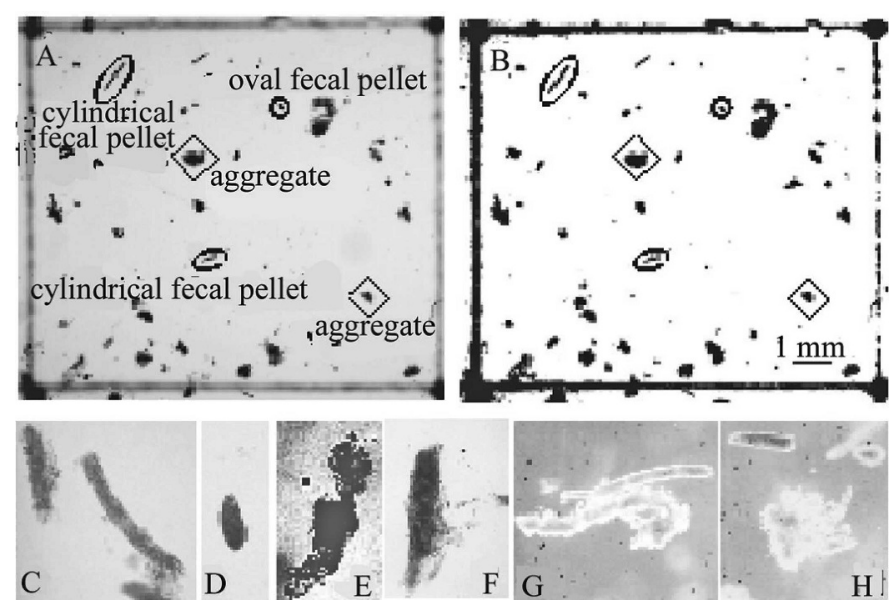

Fig. 2. Images of particles in the gels. (A) One of the $\sim 30$ grid cells (14 mm across) examined for each gel, with different particle types indicated. (B) The same image after thresholding to produce a binary image for particle analysis. The three classified particle types are shown: (C) cylindrical pellet, (D) oval pellet, (E) aggregate, followed by images illustrating fecal pellet transformations: (F) fecal material loosening up, $(\mathrm{G})$ pellets sticking together (lower one in the process of degradation), $(\mathrm{H})$ an aggregate of fecal pellets and other material. Panels $\mathrm{C}-\mathrm{H}$ are $\sim 1 \mathrm{~mm}$ across.

up to $\times 115$ ) and inverted compound microscopy (Leica DM IRB at up to $\times 400$ ). Whereas all of the quantitative results presented here are based on the shipboard analyses, the laboratory analyses confirmed the shipboard result that most aggregates were formed from degraded, agglomerated fecal pellets. The significantly advanced particle degradation prior to laboratory analysis helped in some aspects of particle identification, e.g., the removal of organic matter increased the transparency of pellets and aggregates allowing their contents to be examined in greater detail, but hindered other aspects, e.g., fecal pellets lost some of their structural integrity.

To obtain particle statistics, the entire gel was photographed against an etched-glass grid of 36 cells (each $14 \mathrm{~mm} \times 12.5 \mathrm{~mm})$ at a magnification of $\times 6.5$, using lightfield transmitted illumination and a Zeiss Stemi 2000 CS stereo microscope coupled to a Leica DFC280 1.5 million pixel digital camera and Leica Firecam software on an Apple G4 computer. These 32-bit grayscale images were converted into binary images using the U.S. National Institutes of Health free software package ImageJ. Iterative exploration of lighting conditions and image acquisition parameters was used to optimize the process of automated thresholding to ensure that the binary particle images well represented the original sizes and shapes (Fig. 2).

As summarized in the Results section, we chose to classify the particles into three types: cylindrical fecal pellets, ovoid fecal pellets, and aggregates. All of these particles in each gel (thousands) were classified individually by us by comparing the binary and original images, and the image analysis routine was applied to obtain their areas, lengths, and aspect ratios (by fitting ellipses to their areas). This individual assessment allowed us to verify particle boundaries and rectify any misidentifications of particle areas caused by overlap in the images. Because particles less than $150 \mu \mathrm{m}$ in size were uncommon (see Results), we chose to ignore particles smaller than 100 pixels in area $(0.00019$ $\mathrm{cm}^{2}$ ) in the analysis procedure, and thus were also able to avoid spurious "particles" arising from small variations in optical density associated with gel thickness, glass-grid and optical path cleanliness, etc. Based on test processing without this size cutoff, we estimate that this procedure omitted hundreds of "particles" but less than 5\% of the total particle area, and therefore introduced negligible bias in our overall conclusions. Of course, transparent or nearly transparent particles or portions of them are not directly imaged. Inspection at higher magnification $(\times 50$ shipboard and $\times 400$ in Hobart) suggests that nearly transparent materials were often present within aggregates, but because the three-dimensional aggregate structures caused the visible and transparent portions to overlie each other in the two-dimensional images, much of this material was effectively measured.

Conversion of the imaged areas to volumes required some assumptions. For the aggregates and oval fecal pellets we estimated ellipsoidal volumes by assuming the third axis to be equal to the minor axis of the imaged ellipse. Since these shapes were close to isotropic this introduces minor errors. For the cylindrical pellets we estimated cylindrical volumes using the imaged length and width as the length and diameter, respectively. Because the cylindrical pellets had relatively high aspect ratios (long, thin shapes) their imaged areas will underestimate their volumes unless they lie horizontally in the gel. Inspection of the gels from the side revealed that many particles were arranged randomly in terms of their angles to the vertical, although some tendency toward longer fecal pellets lying more horizontally was observed. Assuming random orientation suggests that the areas of the long cylindrical fecal pellets could be underestimated by up to $\sim 36 \%$ (integrating the random distribution over the $\pi / 2$ angles from horizontal to vertical implies a mean imaged length of $2 / \pi$ of the true length). Given the tendency for the cylindrical pellets to lie horizontally, this is a maximum bias and we did not correct for it.

Conversion from particle volume to organic carbon content was the most uncertain step in our estimation of carbon fluxes. Removing particles from the gel was not practical, and attempts to estimate aggregate carbon contents from optical density were not successful because of varying illumination and the lack of a means to calibrate the optical observations. Therefore we relied on published carbon content analyses. For the fecal pellets, we used a value of $0.057 \mathrm{mg} \mathrm{C} \mathrm{mm}^{-3}$ (Gonzalez and Smetacek 1994). This is a midrange value based on estimates for copepod fecal pellets that range from 0.05 to $0.11 \mathrm{mg} \mathrm{C}$ $\mathrm{mm}^{-3}$ (Silver and Gowing 1991; Gonzalez and Smetacek 1994; Carroll et al. 1998). For the aggregates, we used a more complex relation between size and carbon content. For large aggregates (greater than $0.004 \mathrm{~mm}^{3}$ in volume; or an equivalent spherical diameter [esd] of $\sim 0.02 \mathrm{~cm}$ ), we used a fractal relationship (Alldredge 1998) of POC = $0.99 \mathrm{~V}^{0.52}$ (POC in $\mu \mathrm{g}$ and volume in $\mathrm{mm}^{3}$ ). For smaller aggregates $\left(<0.004 \mathrm{~mm}^{3}\right.$ in volume), we used a linear (i.e., 
Table 2. Particle characteristics and bins for aggregates (agg), cylindrical (cyl), and ovoid (ova) fecal pellets.

\begin{tabular}{|c|c|c|c|c|c|c|c|c|c|c|}
\hline \multicolumn{4}{|c|}{ Characteristics Name } & \multicolumn{2}{|c|}{ Unit } & \multicolumn{5}{|c|}{ Definition } \\
\hline \multicolumn{4}{|l|}{ Area } & \multicolumn{3}{|l|}{$\mathrm{cm}^{2}$} & \multicolumn{4}{|c|}{ pixel area of the particle image } \\
\hline \multicolumn{4}{|c|}{ Volume } & \multicolumn{3}{|l|}{$\mathrm{cm}^{3}$} & \multicolumn{4}{|c|}{ volume calculated from area (see Methods) } \\
\hline \multicolumn{4}{|c|}{ Equivalent spherical diameter (esd) } & \multicolumn{2}{|l|}{$\mathrm{cm}$} & & \multicolumn{4}{|c|}{ diameter of a sphere with the same imaged area } \\
\hline \multicolumn{4}{|c|}{$\begin{array}{l}\text { Perimeter } \\
\text { Perits }\end{array}$} & \multicolumn{2}{|l|}{$\mathrm{cm}$} & \multicolumn{5}{|c|}{$\begin{array}{l}\text { diameter of a sphere with the same imaged area } \\
\text { sum of pixel lengths at particle edge }\end{array}$} \\
\hline \multicolumn{4}{|c|}{ Length } & \multicolumn{2}{|l|}{$\mathrm{cm}$} & \multicolumn{5}{|c|}{ major axis of ellipse fit to particle } \\
\hline \multicolumn{4}{|c|}{ Aspect ratio } & \multicolumn{2}{|l|}{ none } & \multicolumn{5}{|c|}{ major/minor axis ratio of fitted ellipse } \\
\hline \multicolumn{4}{|c|}{ Roughness } & \multicolumn{2}{|l|}{ none } & \multicolumn{5}{|c|}{ ratio of perimeter to ellipse perimeter } \\
\hline \multicolumn{4}{|c|}{ Number flux } & \multicolumn{2}{|c|}{$\mathrm{m}^{-2} \mathrm{~d}^{-1}$} & \multicolumn{5}{|c|}{ number flux of sinking particles } \\
\hline \multicolumn{4}{|c|}{ Volume flux } & \multicolumn{2}{|c|}{$\mathrm{cm}^{3} \mathrm{~m}^{-2} \mathrm{~d}^{-1}$} & \multicolumn{5}{|c|}{ volume flux of sinking particles } \\
\hline \multicolumn{4}{|c|}{ Carbon flux } & \multicolumn{2}{|c|}{$\mathrm{mg} \mathrm{C} \mathrm{m}-2 \mathrm{~d}^{-1}$} & \multicolumn{5}{|c|}{ organic carbon flux in sinking particles } \\
\hline \multicolumn{4}{|c|}{ Number flux size spectrum } & $\mathrm{cm}^{-1}$ & $\mathrm{~d}^{-1}$ & & er flux $p$ & Init esd & interval & \\
\hline Volume $\mathrm{f}$ & ize spect & & & $\mathrm{cm}^{3} \mathrm{c}$ & $\mathrm{m}^{-2} \mathrm{~d}^{-1}$ & & ne flux $p$ & nit esd s & interval & \\
\hline Number & fraction & & & none & & & er flux & irticle ty & as a fract & of total \\
\hline Volume $\mathrm{f}$ & raction & & & none & & & ne flux o & rticle ty & s a fract & of total \\
\hline Carbon $\mathrm{f}$ & raction & & & none & & & n flux of & ticle typ & $\mathrm{s}$ a fracti & f total \\
\hline Bins & & & & & & & & & & \\
\hline Bin limit & 0 & 1 & 2 & 3 & 4 & 5 & 6 & 7 & 8 & 9 \\
\hline esd & 0.0155 & 0.0178 & 0.0252 & 0.0357 & 0.0505 & 0.0714 & 0.1009 & 0.1427 & 0.2019 & 0.2855 \\
\hline
\end{tabular}

solid geometry) dependence on size and a carbon content of 0.25 times that of the fecal pellets.

We chose this piece-wise relation between aggregate size and carbon content for several reasons: (1) for our large aggregates, the fractal power law that parameterizes increasing porosity with increasing size (Alldredge 1998) was consistent with our microscopic observations of aggregate structures; (2) extending this relationship to smaller sizes (less than an esd of $\sim 0.01 \mathrm{~cm}$ ) was clearly not appropriate because it leads to carbon densities for small aggregates that greatly exceed those of phytoplankton and thus a change to a linear relation at smaller sizes is required (Kriest 2002); (3) a carbon content for the small aggregates of 0.25 times that of fecal pellets was consistent with our microscopic observations, suggesting that smaller aggregates were often formed from disaggregating single cylindrical fecal pellets that had approximately doubled in diameter; and (4) using an esd of $\sim 0.02 \mathrm{~cm}$ for the transition from linear to fractal geometry is consistent with compiled mass-size relations (Kriest 2002) and was close to the median size of cylindrical fecal pellets in our samples and thus was appropriate for the transition from small aggregates consisting of disaggregating individual fecal pellets to large aggregates consisting of agglomerated fecal pellets.

While our chosen parameterization for aggregate carbon content is consistent with previous work (Alldredge 1998; Kriest 2002), we emphasize that it probably represents carbon flux to no better than an order of magnitude. This reflects the uncertainties in the published power law as derived from suspended aggregates at shallow Californian coastal waters (Alldredge 1998) and its uncertain applicability to sinking particles at mesopelagic depths in the Southern Ocean. More aggregate carbon measurements are very much needed to improve this situation.

Following the approach of previous studies (Jackson et al. 1997, 2005), we present the particle information as size spectra in units of flux of particle numbers per unit particle size, using an equivalent spherical particle diameter for the size based on the imaged area of the particle (Jackson et al. 2005). Definitions and units for these terms are provided in Table 2, including the bin limits used to construct the spectra. The bins were spaced at a factor of two intervals in terms of the imaged area, with the lowest limit set to the 100 pixel cutoff in imaged area and the highest limit set to ensure several particles were present (i.e., to ensure statistically appropriate sampling; Jackson et al. 1997).

\section{Results}

The polyacrylamide-gel sediment traps deployed at the central KEOPS high-biomass Sta. A3 and at the peripheral moderate-biomass Sta. C5 (Fig. 1 and Table 1) performed very well in terms of collecting intact sinking particles as shown by the fragile forms preserved in the gels (Fig. 2). The short duration $(\sim 1 \mathrm{~d})$ of the trap deployments avoided overloading the gels and facilitated the image processing. The particles were evenly distributed over the collection area of the gels, in contrast to some previous studies (Whiteley 2003), suggesting vertical deployments and a negligible flow of the gel within the trap.

The first notable aspect of the materials collected in the gel traps was the absence of significant numbers of zooplankton. There were at most one to two copepods per trap, and a single euphausid in one trap, despite their high abundances and dominance of surface net collections (Carlotti et al. 2006). There were similarly small numbers of acantharia but slightly higher numbers of pelagic tunicates and especially foraminifera, which reached $\sim 10$ per gel. No further quantification or identification of zooplankton was pursued. The low numbers of copepods and euphausids possibly reflect the absence of poisons in the traps but may also be due to the gels themselves discouraging zooplankton-since very low zooplankton numbers in gel traps in 
comparison with unpoisoned traps were observed in a later study in the subarctic North Pacific (Trull, Ebersbach, and Buesseler, unpubl. data).

The second notable aspect was the absence of large numbers of individual phytoplankton, small fecal "minipellets" $(<100 \mu$; as derived from heterotrophic nanoflagellates and other small protists; Gonzalez 1992b; Gowing et al. 2001; Turner 2002), eggs, or other small particles. Some individual large diatom frustules were present (primarily large centric and pennate diatoms but also including a few 1-3 mm long Thalasiothrix antarctica needle-like frustules), but the total contribution of individual phytoplankton was estimated as less than $1 \%$ of the particle population. For this reason we used a cutoff of $\sim 150 \mu \mathrm{m}$ equivalent spherical diameter (esd) for the smallest particles in our image processing and thus did not quantify this contribution further.

The third notable aspect was the presence of many large fecal pellets and aggregates of these pellets, examples of which are shown in Fig. 2. Cylindrical pellets were most common. These included (1) highly cylindrical pellets with very smooth borders and nearly invariant diameters that appeared to contain fine materials, these were commonly brown or tan in color; (2) pellets that tapered slightly over their length, these were often among the largest pellets, exhibited similar or slightly lighter colors, and did not appear to be as tightly packed as the former; (3) relatively short, only approximately cylindrical pellets with very rough edges that appeared to contain large diatom frustules. Of these three subtypes of cylindrical pellets, the first was by far the most common. In addition there were small numbers of distinctly ovoid fecal pellets, which were usually very black and tightly packed, similar to those reported in Antarctic waters (Gonzalez 1992a).

The highly cylindrical fecal pellets were probably derived from copepods, based on morphological similarity to previous identifications (Honjo and Roman 1978; Gonzalez and Smetacek 1994) and the observation that large copepods along with less abundant euphausids dominated net samples during KEOPS (Carlotti et al. 2006). The rarer large, tapering, cylindrical, less tightly packed fecal pellets were probably from euphausids, again based on morphological similarity to previously studied pellets (Gonzalez 1992a; Gonzalez et al. 1994; Waite et al. 2000). The origin of the ovoid fecal pellets in our study, as in previous work (Gonzalez 1992a), remains unknown. These ovoid pellets were almost always observed singly rather than within aggregates, suggesting that they do not readily stick to other particles.

Aggregates were the most abundant particle type. They were generally approximately isotropic in shape, commonly contained of the order of two to eight cylindrical pellets or pellet fractions and were brown in color (Fig. 2). There was little evidence for loose aggregates formed by direct flocculation of relatively undamaged phytoplankton, e.g., as observed in the Pacific by in situ examination of suspended particles (Alldredge and Gotschalk 1988), in gel traps in a Swedish fjord (Waite et al. 2005), and during the Southern Ocean iron enrichment experiment (SOIREE; Waite and Nodder 2001; Jackson et al. 2005). For example, loose aggregates of the long (1-2 mm) needle-like diatom $T$. antarctica, large spiral-chain forms of Eucampia antarctica, or other large diatoms that were present in surface waters (Armand et al. 2006) were not observed. Loose amorphous aggregates without internal structure as observed during SOIREE (Waite and Nodder 2001), where they were attributed to physical aggregation, or in subantarctic waters (Waite et al. 2000), where they were thought to possibly derive from disaggregating salp fecal pellets, were not observed either.

The general internal structure of the aggregates seemed to be related to the agglomeration of cylindrical fecal pellets - often pairs of pellets were arranged in parallel, and others in crossing shapes. Pellets grouped around nearly transparent material including transparent exopolymeric particles or appendicularian molts were also observed, but were less common. Many of these pellets were in the process of disaggregating (Fig. 2), and exhibited loosening of material, opening out of their shapes, and spreading of their tightly packed contents in very similar ways to that observed for copepod pellets in the laboratory (Honjo and Roman 1978). Studies of the incorporation of radio-labeled compounds (Turley 1993; Bidle and Azam 1999; Turley and Stutt 2000) have demonstrated that this degradation is mediated by bacteria, and as reviewed by Turner (2002) includes activity internally as well as on external surfaces. Along with pellet disruption by physical processes and zooplankton feeding, this bacterial activity is an important contributor to the vertical flux (Lampitt et al. 1991; Noji et al. 1991; Silver and Gowing 1991). As disintegration proceeds, the fecal pellets become less identifiable and eventually indistinguishable from what might have been flocculated phytoplankton (as is evident from comparison to other studies of aggregates in gels, Waite et al. 2000; Waite and Nodder 2001). This means that we cannot rule out a role for physical aggregation of phytoplankton, although we consider it to have been a minor contributor to export.

Given the dominant abundance of the aggregates and the subjective nature of distinguishing the three subtypes of the cylindrical pellets, we chose to quantify three types of particles: (1) cylindrical fecal pellets, (2) oval fecal pellets, and (3) aggregates. In our classification, the term "aggregate" means that a particle was not distinctly recognizable as a single fecal pellet, an animal, or an individual phytoplankton cell. Based on low-power shipboard microscopy (up to $\times 50$ ) most of these aggregates were composed of agglomerated cylindrical fecal pellets (see Fig. 2). The higher magnification microscopy in Hobart 4 months later revealed the evolution of particle forms during their degradation and suggested that many of the smaller particles identified shipboard as aggregates may have formed from degraded individual fecal pellets. Thus our overall qualitative conclusion was that most of the flux was derived from copepod fecal pellets, sinking either individually as intact pellets, individually as degrading pellets, or most commonly as aggregates of pellets in various states of decay.

The image analysis procedure allowed us to classify the vast majority of collected particles into these three types (in 


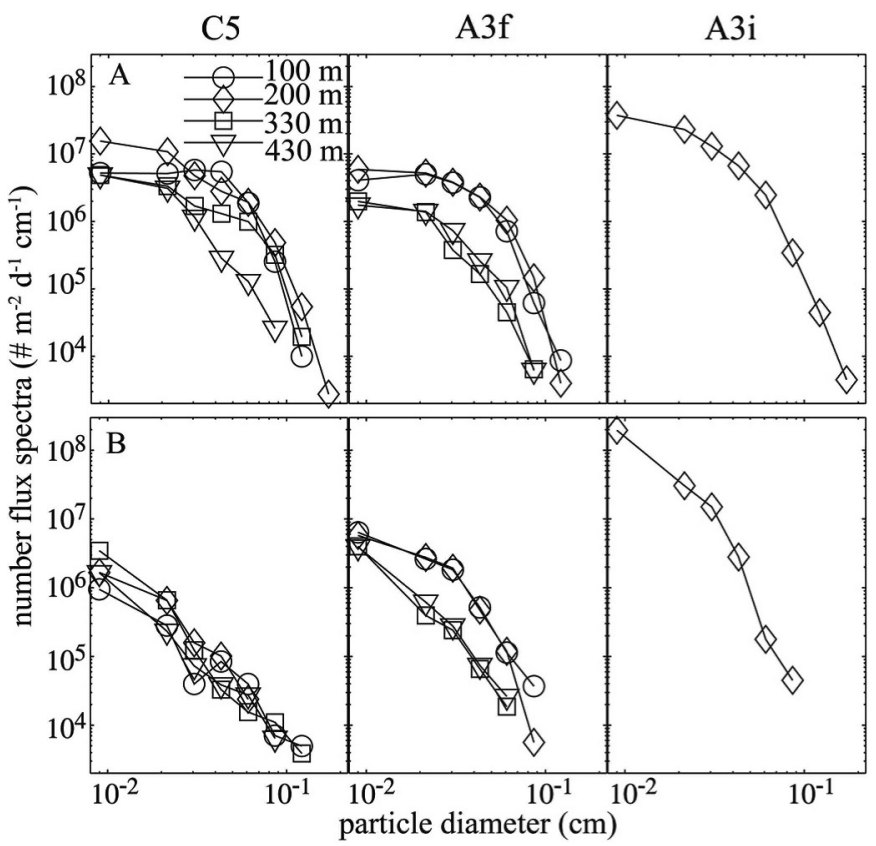

Fig. 3. Number flux spectra (A) aggregates, (B) cylindrical fecal pellets. Aggregates were in general larger than cylindrical fecal pellets. Both types decreased in size with depth in the water column.

excess of $90 \%$ and often $95 \%$ of the areas of the images occupied by particles) and to determine their total fluxes, sizes, shapes, and other characteristics (Table 2 provides a short summary of our particle measurement terminology and associated units). First we present the total fluxes of the particles across the three types, in terms of both numbers of particles and volumes of particles (in Tables 3 , 4 , and 5). Then we examine size distributions for the cylindrical fecal pellets and the aggregates in Figs. 3, 4, and 5 (but not for the oval fecal pellets because of the small numbers collected). Finally we consider the shapes of the cylindrical fecal pellets and aggregates (Fig. 6). We emphasize the results from $\mathrm{C} 5$ and the final visit to $\mathrm{A} 3$ (A3f), for which information was obtained at four depths (Table 1), but also provide results from the initial visit to A3 (A3i) for which results are available only from 200-m depth (and may have been compromised during trap recovery; see the Methods section).

Total number fluxes were highest in the $\mathrm{C} 5$ collections at $100-$ and $200-\mathrm{m}$ depths (Table 3 ) and slightly exceeded the total number fluxes at A3f at these depths, by $29 \%$ and $6 \%$, respectively. Deeper in the water column, total number fluxes decreased strongly at both sites - to approximately one third to one half of $100-\mathrm{m}$ values at $330-$ and $430-\mathrm{m}$ water depth. Aggregates were the dominant particle type, contributing at least $49 \%$ of the particles in the C5 and A3f collections at all depths, and generally much more, ranging up to $96 \%$ in the C5 100-m trap (Table 3). This dominance was stronger at $\mathrm{C} 5$ than at $\mathrm{A} 3 \mathrm{f}$ and decreased with depth at both sites. After aggregates, cylindrical fecal pellets were the next most important particle type. Their importance was larger at A3f (27\% to $37 \%$ of total numbers) than at C5 (3\% to $12 \%$ of total numbers). This difference is

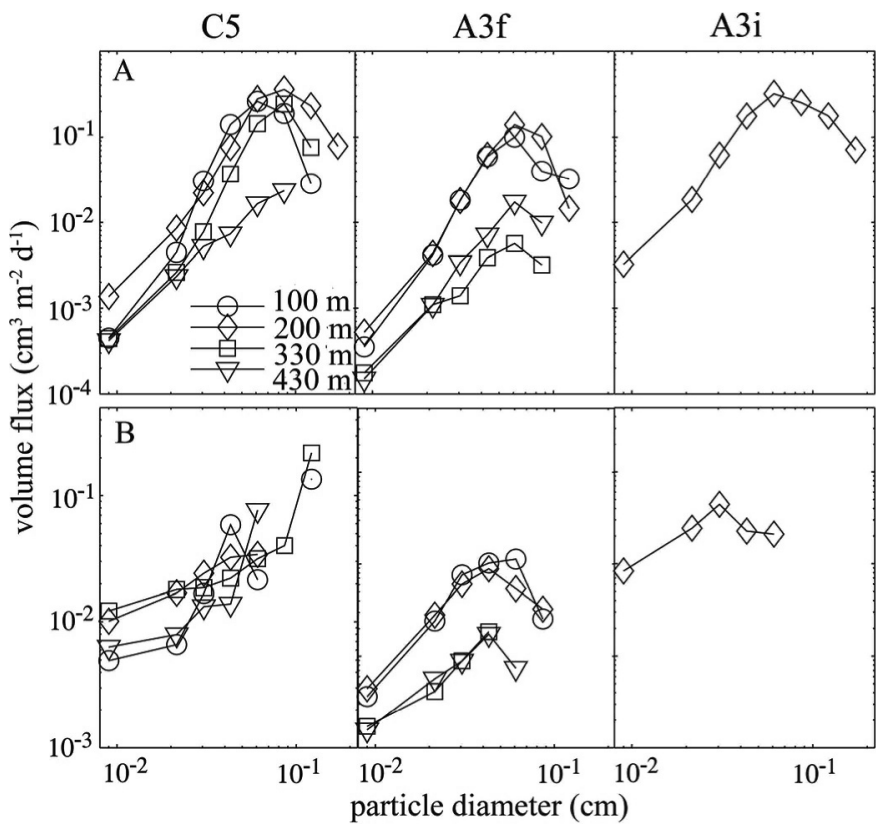

Fig. 4. Volume flux as a function of particle size. (A) Aggregates and (B) cylindrical fecal pellets. Medium-sized particles dominated the volume fluxes, in contrast to the dominance of number fluxes by small particles (Fig. 3).

emphasized by considering the ratio of aggregates to cylinders (which exceed 30 at $\mathrm{C} 5$ but was less than 3 at A3f). Oval pellets were the minor player in all collections except at $\mathrm{C} 5430 \mathrm{~m}$, where they reached $17 \%$ of total numbers and exceeded the $10 \%$ contribution from cylindrical pellets. The compromised A3i 200-m trap was distinguished by a much higher flux than any other trap

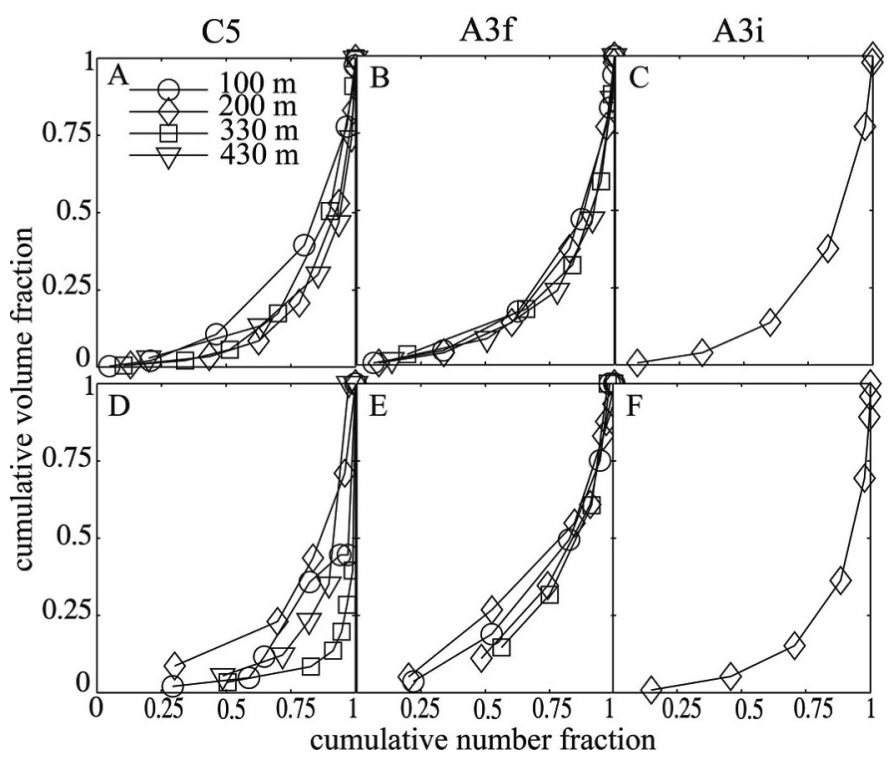

Fig. 5. Cumulative carbon flux as a function of cumulative number flux summed across increasing size classes. (A-C) Aggregates, (D-F) cylindrical fecal pellets. The largest $20 \%$ of the particles contributed more than $50 \%$ of the carbon flux at all sites and depths. 


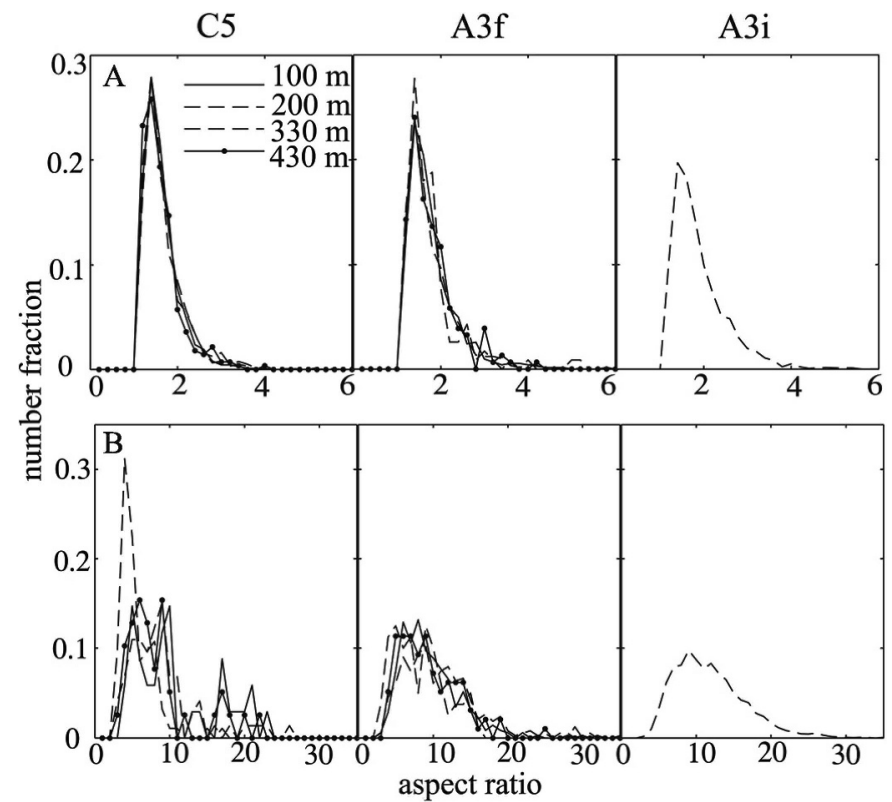

Fig. 6. Changes in particle shape with depth and among the sites. (A) Aggregate aspect ratios and (B) cylindrical fecal pellet aspect ratios. The aggregates had a narrow range of aspect ratios and very similar aspect ratio distributions in all the samples. In contrast, the cylindrical fecal pellet aspect ratios varied more than an order of magnitude.

(approximately four times higher) and a much greater contribution from cylindrical fecal pellets to the total flux (58\%, Table 3).

Examining the particle fluxes in terms of volume fluxes underlines the trends observed in the particle number statistics. Volume fluxes were higher at $\mathrm{C} 5$ than $\mathrm{A} 3 \mathrm{f}$ and decreased strongly with depth, with the results for 330- and 430-m representing as little as $10 \%$ of those at the surface (Table 4). Aggregates contributed more than $77 \%$ of the total volume flux in all traps (Table 4) in comparison with greater than $48 \%$ of the number flux, reflecting the larger size of the aggregates in comparison with the fecal pellets (as indicated by the median dimensions for the particles presented in Table 5).

The smallest particles $(\sim 0.01 \mathrm{~cm})$ were most abundant at all the sites (Fig. 3). There was a strong decrease of more than two orders of magnitude in terms of number flux per unit size (diameter) across the observed size range from 0.01 to $0.1 \mathrm{~cm}$ (see Table 2 for bin sizes used to construct Figs. 3, 4, and 5). For both aggregates and cylindrical fecal pellets, the general trend of decreasing size and number flux with depth (Fig. 3) was noted earlier by reference to median particles sizes (Table 5).

Although small particles dominated the aggregate and especially the cylindrical fecal pellet number flux spectra (Fig. 3), their contribution to the volume flux was not as important. Midrange particle sizes (in particular from 0.02 to $0.08 \mathrm{~cm}$ ) were most important to the volume fluxes (Fig. 4). The trend toward a greater contribution from small particles at deeper depths noted for the number flux above was still discernable but much less pronounced. This is in part because the small particles contributed less importantly to the volume flux than the number flux, and in part because variations in the abundance of the largest size classes dominated the control of the volume flux variations (this latter effect is particularly evident in the results for aggregates at site C5 in Fig. 4). In general, a narrower range of aggregate sizes was important to the volume flux than for cylindrical fecal pellets. Although very large fecal pellets and large aggregates were rare, their presence was still important to the control of the volume and carbon fluxes, as is made clear in Fig. 5. For all the samples, $50 \%$ of the carbon flux comes from the large particles that make up less than $20 \%$ of the number flux, and conversely the small particles that make up more than $50 \%$ of the total number of particles contribute less than $20 \%$ of the carbon flux.

Aggregates contributed at least $77 \%$ of the total volume flux in all the traps, and often exceeded 95\% (Table 4). In terms of carbon contents, their role was considerably reduced but still dominant at shallow depths (100 and $200 \mathrm{~m}$ ) at site C5, where they made up $74 \%$ and $85 \%$ of the carbon flux. This influence decreased at depth (330 and $430 \mathrm{~m}$ ) to $49 \%$ and $33 \%$. At A3, the aggregate contribution to carbon flux was limited to $25 \%$ to $36 \%$ at all depths, again with a slight decrease in its importance with depth.

Particle shape variations for the cylindrical fecal pellets and the aggregates differed dramatically. Aspect ratios of the latter were in a narrow range (mostly between one and approximately four, none above eight) and their distribu-

Table 3. Contributions to the total number flux.

\begin{tabular}{|c|c|c|c|c|c|c|c|c|}
\hline \multirow[b]{2}{*}{ Site } & \multirow[b]{2}{*}{ Depth (m) } & \multicolumn{2}{|c|}{ Aggregates } & \multicolumn{2}{|c|}{ Cylinders } & \multicolumn{2}{|c|}{ Ovals } & \multirow[b]{2}{*}{ Total flux } \\
\hline & & Flux & Fraction & Flux & Fraction & Flux & Fraction & \\
\hline \multirow[t]{4}{*}{$\mathrm{C} 5$} & 100 & 24 & 0.96 & 1 & 0.03 & 0.3 & 0.01 & 25 \\
\hline & 200 & 26 & 0.94 & 1 & 0.04 & 0.6 & 0.02 & 28 \\
\hline & 330 & 10 & 0.84 & 2 & 0.12 & 0.5 & 0.04 & 12 \\
\hline & 430 & 5 & 0.72 & 1 & 0.10 & 1.3 & 0.18 & 7 \\
\hline \multirow[t]{4}{*}{ A3f } & 100 & 14 & 0.68 & 6 & 0.32 & 0.0 & 0.00 & 20 \\
\hline & 200 & 15 & 0.65 & 6 & 0.27 & 2.0 & 0.08 & 23 \\
\hline & 330 & 2 & 0.51 & 2 & 0.36 & 0.5 & 0.12 & 4 \\
\hline & 430 & 3 & 0.48 & 2 & 0.31 & 1.2 & 0.21 & 6 \\
\hline A $3 \mathrm{i}$ & 200 & 55 & 0.37 & 85 & 0.58 & 6.6 & 0.04 & 147 \\
\hline
\end{tabular}

All fluxes in units of $10^{-4} \mathrm{~m}^{-2} \mathrm{~d}^{-1}$. 
Table 4. Contributions to the total volume and carbon fluxes.

\begin{tabular}{|c|c|c|c|c|c|c|c|c|c|}
\hline \multirow[b]{2}{*}{ Site } & \multirow[b]{2}{*}{ Depth (m) } & \multirow[b]{2}{*}{ Volume flux } & \multicolumn{3}{|c|}{ Fraction } & \multirow[b]{2}{*}{ Carbon flux } & \multicolumn{3}{|c|}{ Fraction } \\
\hline & & & Agg & Cyl & Ova & & Agg & Cyl & Ova \\
\hline \multirow[t]{4}{*}{$\mathrm{C} 5$} & 100 & 11.6 & 0.98 & 0.02 & 0.00 & 56 & 0.74 & 0.26 & 0.01 \\
\hline & 200 & 14.3 & 0.99 & 0.01 & 0.00 & 49 & 0.85 & 0.14 & 0.01 \\
\hline & 330 & 7.51 & 0.95 & 0.05 & 0.00 & 41 & 0.49 & 0.50 & 0.01 \\
\hline & 430 & 1.20 & 0.85 & 0.10 & 0.05 & 15 & 0.33 & 0.44 & 0.23 \\
\hline \multirow[t]{4}{*}{ A3f } & 100 & 5.36 & 0.86 & 0.14 & 0.00 & 63 & 0.30 & 0.70 & 0.00 \\
\hline & 200 & 6.61 & 0.89 & 0.10 & 0.01 & 62 & 0.36 & 0.58 & 0.06 \\
\hline & 330 & 0.44 & 0.77 & 0.21 & 0.03 & 8 & 0.25 & 0.66 & 0.09 \\
\hline & 430 & 0.86 & 0.81 & 0.13 & 0.07 & 13 & 0.25 & 0.49 & 0.26 \\
\hline $\mathrm{A} 3 \mathrm{i}$ & 200 & 22.2 & 0.82 & 0.17 & 0.01 & 287 & 0.24 & 0.71 & 0.05 \\
\hline
\end{tabular}

Volume fluxes in $\mathrm{cm}^{3} \mathrm{~m}^{-2} \mathrm{~d}^{-1}$, carbon fluxes in $\mathrm{mg} \mathrm{C} \mathrm{m}^{-2} \mathrm{~d}^{-1}$

tions were very similar at all sites and depths (Fig. 6). In contrast, cylindrical pellet aspect ratios ranged much more broadly, up to almost a factor of 30 . Variations with depth were subdued at A3f, but considerable at C5 (albeit without any systematic changes across the four depths). Fragmentation into shorter lengths would seem to be a likely process, but the aspect ratios did not show any systematic trend in this regard, and thus new pellet formation, pellet disaggregation, and other processes appear to also be important. This complexity of controls on fecal pellet types and their variation with depth has been observed in many environments, as reviewed recently by Turner (2002).

\section{Discussion}

The primary objective of this work was to assess the ecosystem processes controlling particulate carbon export in the iron-fueled high productivity region over the Kerguelen plateau and to compare these processes to those of the HNLC waters that prevail throughout the surrounding open Southern Ocean. Because difficult shipboard conditions precluded collection of HNLC sediment trap samples during KEOPS (originally planned for HNLC site $\mathrm{C} 11$ ), we examine the differences between the high-biomass (A3) and moderate-biomass (C5) sites as a guide to possible variations in the control of export as a function of biomass and production levels, and supplement this analysis by comparison with literature results from other Southern Ocean HNLC sites.
Comparison of the gel flux results to biogeochemical estimates-The carbon flux estimates (Table 4) compare reasonably well with two other estimates made during the KEOPS program, given the uncertainties of all these techniques. POC was measured on samples from the PPS3/3 cylindrical sediment trap suspended at $200 \mathrm{~m}$ on the same drifting trap arrays as the gel traps. At each site two cups from the PPS3/3 trap were sieved through a 350$\mu \mathrm{m}$ screen to remove swimmers and filtered onto a $1-\mu \mathrm{m}$ quartz fiber filter and yielded organic carbon fluxes of 18 $20 \mathrm{mg} \mathrm{C} \mathrm{m}^{-2} \mathrm{~d}^{-1}$ for $\mathrm{C} 5,13-20 \mathrm{mg}$ for A3f, and 44-48 mg for $\mathrm{A} 3 \mathrm{i}$ (the ranges represent those obtained from two cups rotated beneath the PPS $3 / 3$ trap during the deployment, Trull unpubl. data). The approximately three to four times higher gel carbon fluxes suggest that our volume to carbon conversion relation overestimates carbon fluxes, assuming that the larger diameter PPS $3 / 3$ trap and the gel trap had similar collection efficiencies. Estimates of carbon flux at 100-m depth based on water-column ${ }^{234} \mathrm{Th}$ disequilibria combined with $\mathrm{C}:{ }^{234} \mathrm{Th}$ ratios from the PPS3/3 trap and from size-fractionated particle samples obtained with a high-volume pump are approximately twice those obtained from the gels at $\mathrm{C} 5$ and A3f, but similar for A3i, with values of $\sim 130,110$, and $290 \mathrm{mg} \mathrm{C} \mathrm{m}^{-2} \mathrm{~d}^{-1}$ at C5, A3f, and A3i, respectively (Savoye et al. 2006). These differences could be accommodated by a choice of higher carbon contents for the aggregates (see Method section), or lower $\mathrm{C} / \mathrm{Th}$ ratios for exported particles (Savoye et al. 2006). Alternatively, the flux measured punctually by the

Table 5. Median particle volumes and equivalent spherical diameters.

\begin{tabular}{|c|c|c|c|c|c|c|c|}
\hline \multirow[b]{2}{*}{ Site } & \multirow[b]{2}{*}{ Depth (m) } & \multicolumn{2}{|c|}{ Aggregates } & \multicolumn{2}{|c|}{ Cylinders } & \multicolumn{2}{|c|}{ Ovals } \\
\hline & & $\begin{array}{c}\text { Volume } \\
\left(\times 10^{-6} \mathrm{~cm}^{3}\right)\end{array}$ & $\begin{array}{c}\text { esd } \\
\left(\times 10^{-1} \mathrm{~cm}\right)\end{array}$ & $\begin{array}{c}\text { Volume } \\
\left(\times 10^{-6} \mathrm{~cm}^{3}\right)\end{array}$ & $\begin{array}{c}\text { esd } \\
\left(\times 10^{-1} \mathrm{~cm}\right)\end{array}$ & $\begin{array}{c}\text { Volume } \\
\left(\times 10^{-6} \mathrm{~cm}^{3}\right)\end{array}$ & $\begin{array}{c}\text { esd } \\
\left(\times 10^{-1} \mathrm{~cm}\right)\end{array}$ \\
\hline \multirow[t]{4}{*}{$\mathrm{C} 5$} & 100 & 26 & 0.37 & 3.6 & 0.21 & 0.9 & 0.13 \\
\hline & 200 & 12 & 0.28 & 3.4 & 0.20 & 1.3 & 0.15 \\
\hline & 330 & 21 & 0.34 & 2.8 & 0.17 & 1.6 & 0.15 \\
\hline & 430 & 6 & 0.22 & 2.5 & 0.18 & 3.1 & 0.20 \\
\hline \multirow[t]{4}{*}{ A $3 f$} & 100 & 16 & 0.31 & 5.7 & 0.24 & 0.0 & 0.00 \\
\hline & 200 & 15 & 0.30 & 5.4 & 0.24 & 2.5 & 0.18 \\
\hline & 330 & 6 & 0.22 & 2.1 & 0.17 & 2.0 & 0.17 \\
\hline & 430 & 8 & 0.25 & 2.7 & 0.19 & 3.1 & 0.20 \\
\hline A $3 \mathrm{i}$ & 200 & 0.9 & 0.26 & 1.9 & 0.18 & 2.8 & 0.19 \\
\hline
\end{tabular}


gels in this period of a general decline in surface chlorophyll concentrations (see the Introduction) may have been lower than that held sway during the previous few weeks over which the ${ }^{234} \mathrm{Th}$ method integrates (Buesseler et al. 2006).

Comparison of the high (A3) and moderate (C5) biomass sites - The formation of fecal pellets and their aggregates was the key process responsible for particle export at A3 and C5. Direct export of large cylindrical fecal pellets was secondary in terms of volume flux but of similar importance in terms of carbon export (Table 4). Contributions from "minipellets" $(<100 \mu \mathrm{m})$, single phytoplankton cells, or phytoplankton dominated aggregates (phytodetritus) were negligible. This suggests that the dominant control on export is biological aggregation of phytoplankton into fecal pellets by large zooplankton, followed by further agglomeration into large aggregates by either physical or biological processes.

At both sites, particle fluxes decreased strongly with depth, particularly between the two shallower traps (100 and $200 \mathrm{~m}$ ) and the two deeper traps (330 and $430 \mathrm{~m}$ ). For comparison with open ocean environments, we plotted the KEOPS carbon flux estimates against power-law curves used to parameterize observed open ocean flux attenuation with depth (Martin et al. 1987; Buesseler et al. 2007). Comparing the deepest $(430 \mathrm{~m})$ and shallowest $(100 \mathrm{~m})$ traps, the KEOPS carbon flux attenuation at both sites was very similar to open ocean observations (Fig. 7). At C5, the intermediate depth traps displayed higher carbon fluxes than expected from the open ocean power law, suggesting relatively little flux attenuation between 100 and $330 \mathrm{~m}$. At A3, this behavior was observed only between 100- and 200$\mathrm{m}$ depth, with the flux decreasing rapidly between the 200and 330-m traps. The relatively large variations with depth, (approximately fivefold at A3f and approximately fourfold at C5) may be a real characteristic of the flux of large particles over these mesopelagic depths - a depth range for which very few data are available (Martin et al. 1987; Buesseler et al. 2007).

Comparing the $\mathrm{A} 3$ and $\mathrm{C} 5$ sites, the number and volume fluxes were somewhat larger at the moderate biomass site (C5) than at the high-biomass site (A3f) although carbon fluxes were similar, (Tables 3 and 4). Decreases with depth also differed in terms of both total fluxes (Fig. 7) and details of the changes in particle size distributions (Fig. 4). Other estimates of export or correlated properties suggest the probability of a greater flux at the A3 bloom site than at C5: approximately twofold higher primary production at A3f based on ${ }^{14} \mathrm{C}$ incubations (Griffiths and Uitz 2006) and approximately twofold higher export at A3f based on ${ }^{234} \mathrm{Th}$ deficits (Savoye et al. 2006).

It is possible that the two- to threefold uncertainties associated with the hydrodynamics of particle collection into drifting sediment traps (Gardner 2000) has biased the gel-trap results, but the temporal decoupling of export from primary production, from particle standing stocks, and from the longer timescales (several weeks) over which the ${ }^{234} \mathrm{Th}$ method integrates export (Buesseler et al. 2006) could also explain these differences. Given the uncertainties in all the methods and the similarity of the particle types

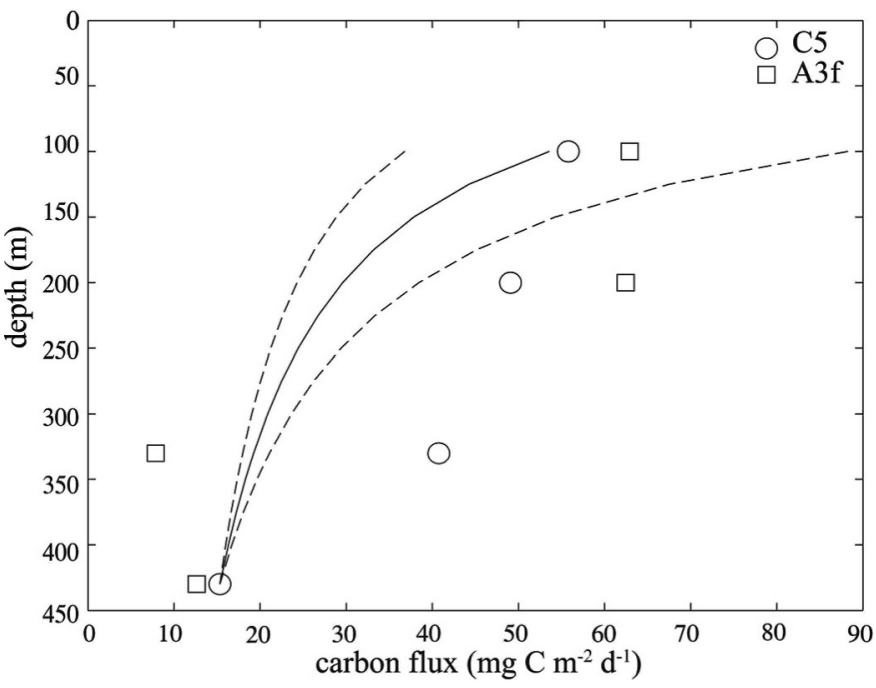

Fig. 7. Variations of KEOPS carbon fluxes with depth in comparison with commonly applied power-law parameterizations for flux attenuation, flux $(z)=$ flux $(100 \mathrm{~m}) \times(z / 100)^{-b}$, as estimated from drifting traps (solid curve from Martin et al. 1987 for $b=0.858$ ) and moored traps (dotted curves indicate bounds for $b$ of 0.6 and 1.2; Boyd and Trull 2006).

collected, the most robust conclusion is that the controls on export were similar at the epicenter (A3) and the periphery (C5) of the Kerguelen bloom.

Comparison to other Southern Ocean studies-Comparing the KEOPS particle characteristics to results from Southern Ocean HNLC sites is hampered by a lack of observations from drifting traps. The only other drifting gel-trap study in polar open ocean waters was carried out during the short-term SOIREE. During this 13-d experiment in HNLC waters of the Antarctic circumpolar current south of the Polar Front in February 1999 (Boyd et al. 2000), gel traps were deployed within and outside of the artificially iron-fertilized "patch" for several periods of 2 to $3 \mathrm{~d}$ (Waite and Nodder 2001). The in-patch and out-patch traps collected very similar total fluxes (Nodder et al. 2001), and carbon isotopic compositions suggested little increase in flux induced by the iron fertilization (Trull and Armand 2001), which was consistent with ${ }^{234} \mathrm{Th}$ results (Charette and Buesseler 2000). However, measurements of the size distribution of aggregates in the SOIREE gels suggested a small increase in particle size in the in-patch traps in comparison with the out-patch HNLC waters (Waite and Nodder 2001; Jackson et al. 2005). Thus the SOIREE geltrap size distribution results (Jackson et al. 2005) offer the possibility to compare the KEOPS results with both export from Southern Ocean HNLC waters (the SOIREE outpatch results) and with export following an artificial iron fertilization (the SOIREE in-patch results).

During SOIREE the distribution of particle sizes (both in-patch and out-patch) was dominated by smaller particles than those dominating the KEOPS traps, including a large contribution from individual pennate and centric diatoms of a few hundred microns in size, along with diatom aggregates that were considered to have formed by 
coagulation (Waite and Nodder 2001; Jackson et al. 2005). Fecal pellet statistics from the SOIREE gels have not been published, but their abundance was low (Waite and Nodder 2001; Jackson et al. 2005), and negligible mesozooplankton grazing was observed (Zeldis 2001). Interestingly, the particle number flux spectra from SOIREE (both in-patch and out-patch) exhibit values of $10^{9}$ decreasing to $10^{7} \mathrm{~cm}^{-1} \mathrm{~m}^{-2} \mathrm{~d}^{-1}$ across the size interval from 0.01 to $0.1 \mathrm{~cm}$ (Jackson et al. 2005), for which the KEOPS number spectra exhibit a similar decrease but much lower values (107 decreasing to $10^{5} \mathrm{~cm}^{-1} \mathrm{~m}^{-2} \mathrm{~d}^{-1}$; Fig. 3). The 100 -fold higher particle flux numbers were a surprise given that organic carbon fluxes estimated for SOIREE from freedrifting sediment traps and ${ }^{234} \mathrm{Th}$ disequilibria ( $\sim 90$ to $160 \mathrm{mg} \mathrm{C} \mathrm{m}{ }^{-2} \mathrm{~d}^{-1}$; Charette and Buesseler 2000; Nodder and Waite 2001; Waite and Nodder 2001) were similar to those estimated for KEOPS using these methods $(\sim 20$ $50 \mathrm{mg} \mathrm{C} \mathrm{m}{ }^{-2} \mathrm{~d}^{-1}$ from the traps, Trull unpubl. data, and 100-300 mg C m ${ }^{-2} \mathrm{~d}^{-1}$ from ${ }^{234} \mathrm{Th}$ disequilibria, Savoye et al. 2006). This difference raises the importance of variability in the volume-carbon conversion relation for marine particles (see the Methods section). The SOIREE particles in this $0.01-$ to $0.1-\mathrm{cm}$ size range were predominantly fluffy diatom aggregates (Waite and Nodder 2001; Jackson et al. 2005), while those during KEOPS were tightly compacted fecal pellets and aggregates of those pellets.

In comparison with the SOIREE results, the KEOPS results suggest that persistent natural iron inputs lead to a much greater fraction of export being derived from zooplankton fecal pellets and large aggregates than occurs in either Southern Ocean HNLC waters (SOIREE outpatch results) or following artificial iron fertilization of these waters (SOIREE in-patch results). This perspective needs to be tempered by the fact that coupling of phytoplankton production, zooplankton grazing, and the magnitude of particle export is highly variable seasonally (Wassmann 1998), and thus both the SOIREE and KEOPS results represent brief moments in possibly large-amplitude variability in this coupling.

The Kerguelen time series study (Kerfix) in HNLC waters to the west of Kerguelen Island offers another useful comparison for the KEOPS results. Direct studies of exported particle characteristics are not available, but synthesis of carbon budgets (Jeandel et al. 1998) and simulation of seasonal cycles is consistent with zooplankton grazing control of phytoplankton biomass, without a requirement for physical phytoplankton aggregation to enhance export (Mongin et al. 2006). Observations of zooplankton populations and feeding experiments also suggest that zooplankton are capable of removing all primary production in this Indian sector of the Southern Ocean (Mayzaud et al. 2002). Thus, in contrast to the comparison with the SOIREE results, it appears that zooplankton mediated removal of biomass may be similarly important in HNLC waters near the Kerguelen plateau as it is in the high-biomass waters over the plateau. This result is consistent with the observation of generally similar zooplankton population structures on-plateau and off-plateau during KEOPS, but with more of the largest class of zooplankton present on-plateau in the high- biomass region (Carlotti et al. 2006). More detailed comparisons with other observations of particle export and its coupling to primary production and ecosystem structure are beyond the scope of this paper and hampered by the short period of the KEOPS export observations. Additional discussion of these issues is available in Dunne et al. (2005) and Boyd and Trull (2006).

Implications for the response of carbon export to persistent iron fertilization-Two aspects of our limited observations merit emphasis, in the context of attempting to understand the sensitivity of ecosystem structure and carbon export to natural and artificial iron fertilization: (1) direct export of phytoplankton or phytoplankton aggregates was negligible, (2) zooplankton grazing, large fecal pellet formation, and in particular agglomeration of large fecal pellets into large aggregates controlled export.

These results differ from those of Southern Ocean shortterm iron-fertilization experiments, in which zooplankton responses have generally (Boyd et al. 2000; Coale et al. 2004) but not always (Peeken et al. 2006) been muted. Moreover, they differ from the view that nutrient-rich waters that develop high biomass usually export a significant fraction of it directly as phytoplankton aggregates rather than via fecal pellets from higher trophic levels (Boyd and Newton 1995, 1999; Turner 2002). Whether this difference simply reflects the short-term aspect of the KEOPS observations or a more fundamental aspect of persistently iron-fertilized Southern Ocean waters is not yet clear and will require more sustained observations of the mechanisms of export.

Possible reasons why zooplankton might have been more important during KEOPS than during artificial iron fertilizations include the predictability of the annually occurring Kerguelen plateau phytoplankton bloom and the relatively modest phytoplankton levels that develop within it ( $\sim 3 \mu \mathrm{g} \mathrm{Chl} a \mathrm{~L}^{-1}$, Blain et al. 2007), which are close to those estimated to be sufficient to induce efficient aggregation (Jackson and Lochmann 1993; Boyd et al. 2005; Jackson et al. 2005). There is evidence for an important role for zooplankton in export from other recent gel-trap studies in polar waters. Euphausid fecal pellets dominated export in subantarctic waters east of New Zealand (Waite et al. 2000) and in Antarctic coastal waters in Prydz Bay (Whiteley 2003). In contrast, phytodetritral aggregates were important in Antarctic waters during SOIREE, both in and outside the iron-fertilized waters (Waite and Nodder 2001; Boyd et al. 2002; Jackson et al. 2005), during the Subarctic Ecosystem Response to Iron Enrichment Study (SERIES) (Boyd et al. 2005), and in polar waters in a Swedish Fjord (Waite et al. 2005). These differences emphasize that site, season, and ecosystem specific controls on carbon export are likely to be the rule rather than the exception.

\section{References}

Alldredge, A. L. 1998. The carbon, nitrogen and mass content of marine snow as a function of aggregate size. Deep-Sea Res. I 45: 529-541. 
, AND C. Gotschalk. 1988. In situ settling behavior of marine snow. Limnol. Oceanogr. 33: 339-351.

Armand, L. K., V. Barthaux, And B. Queguiner. 2006. Phytoplankton responses within and peripheral to the naturally iron-fertilized Kerguelen region. ASLO-TOS-AGU Ocean Sciences meeting abstracts, OS35M-08.

Bidle, K. D., And F. Azam. 1999. Accelerated dissolution of diatom silica by marine bacterial assemblages. Nature 397: 508-512.

Blain, S., AND others. 2007. Impacts of natural iron fertilisation on the Southern Ocean. Nature 446: 1070-1074. [doi:10.1038/ nature 05700].

Boyd, P. W., G. A. Jackson, And A. Waite. 2002. Are mesoscale perturbation experiments in polar waters prone to physical artefacts? Evidence from algal aggregation modeling studies. Geophys. Res. Lett. 29 [doi: 10.1029/2001GL014210].

- AND P. Newton. 1995. Evidence of the potential influence of planktonic community structure on the interannual variability of particulate carbon flux. Deep-Sea Res. I 42: 619-639.

— AND —. 1999. Does planktonic community structure determine downward particulate organic carbon flux in different oceanic provinces? Deep-Sea Res. I 46: 6391.

—, AND T. W. TRull. 2006. Understanding the export of marine biogenic particles: Is there consensus? Prog. Oceanogr. 4: 276-312. [doi:10.1016/j.pocean.2006.1010.1007].

, AND OTHERS. 2000. A mesoscale phytoplankton bloom in the Southern Ocean stimulated by iron fertilization. Nature 407: 695-702.

— AND - 2005. The evolution and termination of an iron-induced mesoscale bloom in the northeast subarctic Pacific. Limnol. Oceanogr. 50: 1872-1886.

Buesseler, K. O., ANd P. W. Boyd. 2003. Does ocean fertilization work? Science 300: 67-68. [doi:10.1126/science.1082959].

—, AND OTHERS. 2006. An assessment of particulate organic carbon to thorium-234 ratios in the ocean and their impact on the application of ${ }^{234} \mathrm{Th}$ as a POC flux proxy Mar. Chem. 100: 213-233. [doi:10.1016/j.marchem.2005.10.013].

— AND —. 2007. Revisiting carbon flux through the ocean's twilight zone Science 316: 567-570. [doi:10.1126/ science.1137959].

Carlotti, F., D. Botha, D. Lefevre, A. Nowaczyk, M. Clement, AND D. VinCENT. 2006. Mesozooplankton size structure and biomass above the Kerguelen Plateau (Southern Ocean) during KEOPS: First results on two contrasted areas. ASLO-TOS-AGU Ocean Sciences meeting abstract, OS35M-13.

Carroll, M. L., J.-C. Miquel, and S. W. Fowler. 1998. Seasonal patterns and depths - specific trends of zooplankton fecal pellet fluxes in the northwest Mediterranean Sea. Deep-Sea Res. I 45: 1303-1318.

Charette, M. A., and K. O. Buesseler. 2000. Does iron fertilization enhance carbon export in the Southern Ocean? Geochem Geophys. Geosyst. 1 [doi:2000GC000069].

Coale, K. H., And others. 2004. Southern Ocean iron enrichment experiment: Carbon cycling in high and low-Si waters. Science 304: 408-414.

Dunne, J. P., R. A. Armstrong, A. Gnanadesikan, and J. L. SARMIENTo. 2005. Empirical and mechanistic models for the particle export ratio Glob. Biogeochem. Cycles 19: GB4026 [doi:4010.1029/2004GB002390, 002005].

GARDNER, W. D. 2000. Sediment trap sampling in surface waters, p. 240-281. In R. B. Hanson, H. W. Ducklow and J. G. Field [eds.], The changing ocean carbon cycle: A midterm synthesis of the Joint Global Ocean Flux Study. International Geosphere-Biosphere Program Block Series. Cambridge Univ. Press.

Gonzalez, H. E. 1992a. The distribution and abundance of krill faecel material and oval pellets in the Scotia and Weddell Seas (Antarctica) and their role in particle flux. Polar Biol. 12: 81-91.

- 1992b. Distribution and abundance of minipellets around the Antarctic peninsula. Implications for protistan feeding behaviour. Mar. Ecol. Prog. Ser. 90: 223-236.

_, F. K. Kurbjeweit, And U. V. Bathmann. 1994. Occurrence of cyclopoid copepods and faecal material in the Halley Bay region, Antarctica, during January-February 1991. Polar Biol. 14: 331-342.

—, And V. S. Smetacek. 1994. The possible role of cyclopoid copepod Oithona in retarding vertical flux of zooplankton faecal material. Mar. Ecol. Prog. Ser. 113: 233-246.

Gowing, M. M., D. L. Garrison, H. B. Kunze, and D. J. Winchell. 2001. Biological components of Ross Sea shortterm particle fluxes in the austral summer of 1995-96. DeepSea Res. I 48: 2645-2671.

Griffiths, F. B., And J. Uitz. 2006. Photosynthetic parameters, size-fractionated chlorophyll and primary production during the KEOPS expedition East of Kerguelen Island JanuaryFebruary 2005. ASLO-TOS-AGU Ocean Sciences meeting abstract, OS35M-09.

Honjo, S., And M. R. Roman. 1978. Marine copepod fecal pellets: Production, preservation, and sedimentation. J. Mar. Res. 36: 45-57.

Jackson, G. A., And S. E. Lochmann. 1993. Modelling coagulation of algae in marine ecosystems, p. 387-414. In J. Buffle and H. P. van Leeuen [eds.], Environmental particles. Lewis Publ., Ann Arbor, Michigan.

Logan, And H. G. Dam. 1997. Particle size spectra between $1 \mu \mathrm{m}$ and $1 \mathrm{~cm}$ at Monterey Bay determined using multiple instruments. Deep-Sea Res. I 44: 1739-1767.

- A. M. WAITE, AND P. W. Boyd. 2005. Role of algal aggregation in vertical carbon export during SOIREE and in other low biomass environments. Geophys. Res. Lett. 32 [doi: 10.1029/2005GL023180].

JEANDEl, C., AND others. 1998. KERFIX, a time-series station in the Southern Ocean: A presentation. J. Mar. Syst. 17: $555-570$.

KRIEST, I. 2002. Different parameterizations of marine snow in a $1 \mathrm{D}$-model and their influence on representation of marine snow, nitrogen budget and sedimentation. Deep-Sea Res. I 49: $2133-2162$.

Lampitt, R. S., T. Noji, and B. V. Bodungen. 1991. What happens to zooplankton faecal pellets? Implications for material flux. Mar. Biol. 104: 15-23.

LunDSGAARD, C. 1995. Use of a high viscosity medium in studies of aggregates, p. 141-152. In S. Floderus, A.-S. Heisakanen, M. Oleson and P. Wassmann [eds.], Sediment trap studies in the Nordic countries 3. Proceeding of the Symposium on Seasonal Dynamics of Planktonic Ecosystems and Sedimentation in Coastal Nordic Waters. Numi Print, Oy.

Martin, J. H., G. A. Knauer, D. M. Karl, and W. W. Broenkow. 1987. VERTEX: Carbon cycling in the Northeast Pacific. Deep-Sea Res. 34: 267-285.

Mayzaud, P., V. Tirelli, A. Errhif, J. P. Labat, S. Razouls, and R. Perissinotto. 2002. Carbon intake by zooplankton: Importance and role of zooplankton grazing in the Indian sector of the Southern Ocean. Deep-Sea Res. II 49: $3169-3188$ 
Michaels, A. F., And M. W. Silver. 1988. Primary production, sinking fluxes and the microbial food web. Deep-Sea Res. 35: 473-490.

Mongin, M., D. M. Nelson, P. Pondaven, and P. Treguer. 2006. Simulation of upper-ocean biogeochemistry with a flexiblecomposition phytoplankton model: C, N and Si cycling and Fe limitation in the Southern Ocean. Deep-Sea Res. II 53: 601-619.

Nodder, S. D., M. A. Charette, A. M. Waite, T. W. Trull, P. W. Boyd, J. Zeldis, and K. O. Buesseler. 2001. Particle transformation and export flux during an in situ ironstimulated bloom in the Southern Ocean. Geophys. Res. Lett. 28: 2409-2412.

, AND A. M. Waite. 2001. Is carbon export in the Southern Ocean enhanced by iron-stimulated increases in biological production? Sediment trap results from an in situ iron enrichment experiment. Deep-Sea Res. II 48: 2681-2702.

Noji, T. T., K. W. Estep, F. Macintyre, and F. Norrbin. 1991. Image analysis of faecal material grazed upon by three species of copepods: Evidence for coprorhexy, coprophagy, and coprochaly. J. Mar. Biol. Assoc. U.K. 71: 46-48.

Peeken, I., AND others. 2006. Effect of in situ iron fertilisation during contrasting seasons - comparison between EisenEx and EIFEX. ASLO-TOS-AGU Ocean Sciences meeting abstract, OS32A-06.

Savoye, N., T. Trull, S. Jaquet, and F. Dehairs. 2006. 234Thbased export production during the KEOPS natural iron fertilization. ASLO-TOS-AGU Ocean Sciences meeting abstract, OS33F-04.

Silver, M. W., And M. M. Gowing. 1991. The 'particle' flux: Origins and biological components. Prog. Oceanogr. 26: 75-113.

Trull, T. W., and L. Armand. 2001. Insights into Southern Ocean carbon export from the $\delta^{13} \mathrm{C}$ of particles and dissolved inorganic carbon during the SOIREE iron fertilisation experiment. Deep-Sea Res. II 48: 2655-2680.
Turley, C. M. 1993. The effect of pressure on leucine and thymidine incorporation by free-living bacteria attached to sinking oceanic particles. Deep-Sea Res. I 40: 2193-2206.

$\longrightarrow$ - AND E. D. Stutt. 2000. Depth-related cell-specific bacterial leucine incorporation rates on particles and its biogeochemical significance in the Northwest Mediterranean. Limnol. Oceanogr. 45: 419-425.

Turner, J. T. 2002. Zooplankton fecal pellets, marine snow and sinking phytoplankton blooms. Aquat. Microb. Ecol. 27: $57-102$.

Waite, A. M., O. Gustafsson, O. Lindahl, and P. Tiselius. 2005. Linking ecosystem dynamics and biogeochemistry: Sinking fractionation of organic carbon in a Swedish fjord. Limnol. Oceanogr. 50: 658-671.

—, AND S. D. Nodder. 2001. The effect of in situ iron addition on the sinking rates and export flux of Southern Ocean diatoms. Deep-Sea Res. II 48: 2635-2654.

, K. A. SAfi, J. A. Hall, and S. D. Nodder. 2000. Mass sedimentation of picoplankton embedded in organic aggregates. Limnol. Oceanogr. 45: 87-97.

Wassmann, P. 1998. Retention versus export food chains: Processes controlling sinking loss from marine pelagic systems. Hybrobiologica 363: 29-57.

Whiteley, M. 2003. The influence of Antarctic krill (Euphausia superba) on carbon fluxes in the Southern Ocean. Honours thesis, Univ. of Western Australia.

Zeldis, J. 2001. Mesozooplankton community composition, grazing, nutrition, and export production at the SOIREE site. Deep-Sea Res. II 48: 2615-2634.

Received: 26 July 2006

Accepted: 21 June 2007

Amended: 31 July 2007 